\title{
Dalit Mainstreaming in Rural Development: An Alterna- tive Approach for Combating Poverty
}

\author{
Rajan Binayek Pasa \\ Lila Bahadur Bishwakarma
}

\begin{abstract}
This paper highlights a traditionally existed problem for an inclusive model of rural development through mobilization of all caste communities and local level social networking in different localities of Dhading District. An exclusive model where particular caste groups hold the vital post of the organizations and command and control the minorities, as a result, Dalits are still lacking far behind in rural developmental mainstreaming. A multidimensional approach was applied to enrich data, for example, semi-structured interviews in particular and focus group discussion (FGD), and informal communication in general. It was aimed to appraise the socio-cultural situatedness of Dalit, Dalit positioning in social networks, and Dalit mobilization towards rural developmental mainstreaming at the one hand. On the other, this study has attempted to way out an alternative approach that is 5Es (i.e., envisioning, educating, empowering, ensuring, and encouraging) model. It could itself monitor, control, and balance the rural development process. Hence, it is a holistic model to mainstream Dalit communities towards their own community development and mobilizing them towards rural development as/for social transformation. The 5Es is a term in which 5 denotes the number of letters of the term 'Dalit' and E denotes the fifth alphabet of A-Z. It principally refers to and focuses on envisioning Dalits' socio-cultural context and vulnerability, educating Dalit children, empowering Dalit people, ensuring their rights and access, and encouraging them to be involved themselves as a way forward to Dalit mainstreaming to combat against poverty challenges. This might be a planned and structured model to sustain the process, the pace, and the practice of rural development activities. It has no doubt that it might be one of the best Dalits centered development approach in which Dalits have empowered themselves for transforming their livelihoods in general and combating against poverty in particular.
\end{abstract}

Keywords: alternative approach and poverty challenges, dalit empowerment, dalit exclusion, rural development

\section{Setting the Scene}

The term 'Dalit' is a socially reconstructed verse of the Vedic term Shudra. It does not have more than socially constructed subjectivity. The Rig Vedic notion has paradoxically attached with the belief that human beings emerged from the Cosmic-being (Brahma): Brahman, Kshatriya, Vaishya, and Shudra from mouth, hands, thigh, and feet respectively (Rig Veda, 10:90). Since the Shudra originated from the feet they were religiously perceived as impure and unholy beings, what a critical Vedic notion! It is, even, a curiosity that how had it happened from those cosmic being with thousands of heads, eyes and feet as explored by Jayaram, V. (n. d.) in his paper entitled: "The Vedic Gods/The Vedic Pantheon". Therefore, it is an astonishing fact that out of thousands of heads and feet which one is able to give birth to so-called Brahmin or so-called Shudra either? Is it a philosophical derailing or a notion to devalue Shudra as a feet-born human being? Nevertheless, the philosophy of social discrimination and Dalitization is, at least, related to Vedic notion. Such a discriminatory notion based on religious belief and scriptures ranked the social value of human beings as superior and inferior to one another. In this vein, Dumont
(1980) describes the caste system ranks the human as superior and inferior to one another (p. 21). Such ideas reasoned to exclude Dalits from democratic living in the society.

It can be acknowledged that development is an endlessly integrated process of utilizing natural resources and human capacity through a practice of indigenous knowledge and skills and science and technological innovations. It has to be guided by certain principles and basic needs of the society. However, the development initiatives have been criticized for a long past as they fail to address some parts of the core aspect of society's basic needs. It is because development initiatives were centered in city lives, thus out of connection with remote life-world for long past. The remote area's life-world, where a giant image of poverty exists, was out of reach to core developmental practice for past centuries which created a huge gap in mainstreaming of different nationalities in gross domestic product. One of the groups of different nationalities the Dalit is sustaining their lives in a vulnerable condition due to socio-cultural situation. The Dalit could not have easy access to getting into social networks and holding leadership positioning due to various reasons. One of the reasons is as asserted by Bishwakarma (2020) socio-culturally caste-based value practice system in Hindu life-world (p. 88). Hence, this This work is licensed under the Creative Commons (C) Rajan Binayek Pasa \& Lila Bahadur Bishwakarma Rajan Binayek Pasa: Assistant Professor at Central Department of Rural Development, Tribhuvan University, Nepal Email: rajan.pasa@cdrd.tu.edu.np

Lila Bahadur Bishwakarma: Kallery Secondary School, Dhading, Nepal Email: vishwakarmalila@gmail.com 
paper has purposed to explore the past scenarios and present practice of rural developmental initiatives in tracking down the Dalit communities into social networking. Before rural developmental principles and initiatives, the rural life-world did not have a good connection with the living world of the urban and cities. Thus, it remained as a life-world out of access to many opportunities. The rural life-world is the area of infrastructural underdevelopment, area of lacking connectivity with cities, and less access in having more opportunities.

The term rural/remote refers to those areas inhabited by a mass of poor people. Rural areas are full of poor families as huge proportions $(82.93 \%)$ of the total population live there, including Dalit. According to Acharya (2008), most of the population live in rural areas with socioeconomically vulnerable life, combating mass poverty and livelihood challenges (p. 181). Indeed, Dalits are living within socioeconomically vulnerable circumstances that most of them are in the situation of either unemployment, underemployment, or low-paid jobs, as a result, many of them are totally dependent on their indigenous knowledge and skills for livelihood for a long past. In this regard, Subedi (2013) states that Dalits were forced to continue their work to sustain food, clothing, and shelter ( $\mathrm{p}$. 70). Therefore, rural lives (full of poor families) are at vulnerability through combating with poverty being substantially isolated from cities and megacities. But, as difficulties of rural lives the solution has rural development philosophy- a changing process of the society with possibilities of maximizing full potentialities of natural and human resources through indigenous knowledge, skills, creativity and innovation, technology and inclusive social mobilization. Furthermore, it is an approach to improving the quality of life providing them possible modern amenities and facilities, thus, it is a holistic approach. The philosophy of rural development always aims to improve lifestyle for maintaining a standard of living of rural people through a multidimensional approach of socio-economic growth within its socio-cultural premises and terrestrial boundary freely. In this vein, Acharya (2008) has stated that rural development is a conceptual process of development and change to exclusively improve socio-cultural life or the rural area (p. 181). Moreover, it can be perceived as a never stopping process of creating opportunities to address their livelihood problems themselves by controlling the loss of benefits for rural economic growth. Hence, it is a leading approach to deal with poverty challenges aiming for sustainable rural development rather than sustaining elitism. But, in contrast, it is equally possible to create a beneficial sphere for new elites.

\section{Background: Dalit Context and Rural Development Mainstreaming}

Dalit are dispersedly found all over the country. According to the population census (2011), the Dalit population covers 13.6 percent (3.6 million) out of the total population which is bigger than the size of the Brahmin (12.2\%) population (CBS, 2012). But in terms of power and politics, Brahmins are absolutely far powerful than Dalit in all wings of the nation including Kshatriya and Vaishya. In such a historical tendency Shudra (Dalit) has to live with a triple layer of oppressive mode of discrimination from Brahmin, Kshatriya, and Vaishya. A reality of castebased discrimination is found in rural areas compare to semi/urban and cities. The Dalitization is a critical notion that critically paralyzes Dalits' social living standard. In this vein, one of the participants explored his view: To be Dalit is equal to have ultimately vulnerable living due to caste-based discrimination (Field-note, March 14, 2020). The core idea of mainstreaming denotes an inclusive model of social mobilization. It is the way to track down all the nationalities into a big road map of social mobility known as social mainstreaming. However, there are still some barriers to practicing inclusive theories in the Hindu life-world due to caste-based hierarchical social structure and social norms and values. One of the most considering parts of the Hindu life-world is a Dalit community, their socio-cultural situation, and livelihood vulnerability. The socially given value to them denotes inferiority. The socalled upper castes who always intend to control and subjugate Dalit they use socio-cultural tool to be superior of the society. Such conceptual practices have supported to be distracted people from the idea of equality and equity. As a result, there is a huge gap in valuing one so-called upper caste and lower caste people. However, the four-fold of Verna, Brahmin, Kshatriya, Vaishya, and Sudra can be acknowledged as a set of the wheels of a four wheeledcart. In such a cart if one wheel gets imbalanced then other wheels get problems to move forward correctly. In such context, for example, if Sudra is one wheel out of four wheels then there is no doubt the role and value of Sudra as equal to the other three wheels of the cart. Then, what does it mean to devalue the Sudra? Then, essentially a question arises, who Sudra were/Dalit are? Nevertheless, many ill-literatures are found which have stated that most of Dalits' livelihood is yet in susceptible condition in rural life-world.

Indeed, the various jargons are used to denote Dalit situatedness and different identities, for example, -a theologically unholy, historically uncivilized, socioculturally untouchable, economically poor, educationally ignorant (illiterate), politically unheard, and socially excluded group of people. As Sagar Shahi (2017) asserts that Dalits are the socially most excluded caste group of Nepal as they are denied the opportunity of equal participation as other castes in social networks (p. 100). In such a context, it is no doubt that Dalit could rarely get the opportunities to be role model cadre in the course of rural developmental mainstreaming and national-level campaigning. So, it essentially needs to be analyzed Dalits' social status, space, and role in social networks. It needs 
to reframe the goals and approaches of rural development being regardless of caste, ethnic and so on. It is urgent since the constitution of Nepal has provisioned and proclaimed that a journey has been already started towards socialism from the standpoint of capitalism. Socialism is a process in which equality and equity can meet at the point of equilibrium. Hence, hopefully, hope that socialism will sweep out feudalism by the near future.

Moreover, development is a process of understanding the real livelihood situation and journey towards improving quality of life by mobilizing available resources and technology creatively and innovatively. It always encourages us to understand where we are and where the destination to reach throughout developmental initiatives. In this vein, Badal (2017) also asserts "Development is a process to understand, where you are and where you want to go by mobilizing available resources with human factors (p. 1)." Likewise, As Chaudhary and Pasa (2015) also argue that rural development seeks to alleviate poverty, mass utilization of resources, commercialization of agriculture, food security, creating opportunities, infrastructural development of rural community, and modernization of the society. Hence, it is a process of maximizing the benefits of limited resources using knowledge, skills (human creativity), and machinery (technology) factors both. Likewise, it is a scientific process of having common benefits from communal efforts towards targeted goals to ensure quality of life. In doing so, social networks are vital to uniting people each other, however, due to sociocultural beliefs, norms, and values some groups of people were traditionally excluded from social mainstreaming, including Dalit. However, the government and its development partner agencies have been tending to support monetarily to address the basic needs of disadvantaged communities but getting failure. Why so, it is because money is not enough in solving all problems created by socio-cultural beliefs, norms, and values. As such context, it is, rather, better to free Dalit from socio-cultural barriers to get access to various opportunity of leadership on social networks. Hence, rural development strategy should, at least, be Dalit friendly/centered because most of Dalit are in vulnerable condition including many rural ethnic communities. Such an approach may address challenges associated with the critical livelihood of backward, marginalized, underdeveloped, and socially excluded people (Shrestha, 2009). The agricultural sector is the backbone of rural livelihood but many Dalits are found either landless or surviving with grains/crops harvesting from tiny pieces of land. It is because; they are traditionally responsible as servicer to so-called upper caste people instead of to be professionally peasants. Rather, they were/are prescribed for the jobs e. g. tailoring, shoemaking, producing tools out of metals, woodcarving, and so on. It evidences that there have traditionally been multidimensional incomegenerating sectors for Dalits' livelihood. So, it had better to focus on the multidimensional approach to promote Dalit' living standard and the real meaning of sustainable rural development.

\section{Problem to be Explored as the Existed Trend}

Development initiatives have to be based on any of sociopolitical and anthropocentric principles. Hence, it needs a model of collaborative practice and participation of whole societies into developmental activities. For this, an individual must have equal access to social networking, such as youth club, mother group, forest consumer committee, drinking water consumer committee, rural road infrastructure community, school management committee, and so on. Such local-level institutions are formed by local people themselves to conduct, control, and monitoring the developmental activities. These institutions are fully authorized by any legal provision, to form, work and exist at their community level. Such grass-root organizations have a social link to one another thus can be known as social networking. But a traditional approach lacks to encircle all caste communities in such social networks, for example, minorities, basically Dalit, are left either at the outskirt of such networks or are not accounted to space in leadership positioning. The Dalit individuals are rarely nominated for head of the committee which is traditionally existed practice in our society. Dalit are still far behind to have cooperated with so-called non-Dalit into the frame of caste-based social structure. Hence, this study has tried to explore traditional practice and present a scenario of Dalits' mobility in rural development.

Viewing such an existing problem of Dalit exclusion we assumed a set of research questions. A) Has the rural development process been being guided to address social discrimination and showing arrows to the poverty demotion? B) Has the rural development strategy been progressed towards solving problems of socio-economic transformation of rural lives? And, C) Whether rural development models are equally being served to the elite, medium, and poor or not? In search of answering such queries, we have proposed the objectives; A) to understand Dalitization from socio-cultural and occupational standpoints, B) to appraise perceptions of Dalit elected leaders on their social positioning and leadership role, and C) to develop an alternative approach towards rural development as/for combating poverty challenges.

\section{Materials and Methods}

Philosophically, we applied a subjective philosophical lens for exploring contextual truths (subjective ontology) through inductive epistemology (explored the beliefs, faiths, and intuitional network of Dalit participants) (Creswell, 2014; Denzin \& Lincoln, 2011). In doing so, we employed an interpretive research paradigm that helped to blend subjective meaning of our interpretation, participant's interpretation, and theoretical interpretation 
through reflective and interpretive genres (Luitel et al., 2009; O'reilly, 2005).

Methodology, we applied a blended approach (informal communication, FGD, and semi-structured interview) including narrative inquiry. Particularly, narrative inquiry focuses on critical life events, exploring holistic views and holds valuable potential for researchers in a broad range of socio-cultural and economic structures (Webster \& Mertova, 2007). The principal attraction of narrative as the method is its capacity to render life experiences, both personal and social; in relevant and meaningful ways (Connelly \& Clandinin, 1990, p. 10). Being narrators, we also focused on storytelling as lived experiences to understand how our nine participants playing a leadership role in local government ${ }^{1}$, narrated their stories and experiences related to social action and the local environment. Purposively, five participants ( 3 male $\& 2$ female) were selected from the Dhunibeshi Municipality (spatially located on core area) and four participants ( 2 males and 2 females) were selected from Galchhi Rural Municipality (peripheral area) (Field Study, 2020). The caste belongingness of respondents was 2 were from Kami, 4 were from Damai, and 3 were from Sarki. By religion 7 participants are Hindu and remained is Christian. In terms of academic status, 2 males completed a bachelor's degree and 3 females had achieved high school graduation, remained are literate. By occupation, 3 males are teachers, one is social mobilizer and some others engage in agriculture activities and social works. While generating narrative information, quality standard techniques such as informed consent, verisimilitude, transferability, and trustworthiness have been considered (Denzin \& Lincoln, 2011). To get further access to secondary data official profile of both rural/municipalities has been studied.

\section{The Research Field at a Glance}

Dhading district occupies $1926 \mathrm{~km}^{2}$ out of the total area of Nepal. Its topography ranges from a peak of 7409 meter Ganesh Himal to 300-meter lowland (Jogimara) from the sea level. Kathmandu, Rasuwa, Nuwakot, Gorkha, Chitwan, and Makawanpur districts are geographically connected with Dhading. It had 49 VDCs (village development committees) and a Municipality as of the old administrative structure of Nepal. Now, these 49 VDCs have been restructured into 13 local governing bodies. Out of these 13 two (Nilakantha and Dhunibeshi) are municipalities and remaining Gajuri, Galchhi, Gangajamuna, Khaniyabash, Jwalamukhi, Netrawati, Rubi Valley, Thakre, Tripurasundari, Siddhakekh, and Benighat-rorang are Rural Municipalities. However, we selected only two (Galchhi Rural Municipality and Dhunibeshi Municipality) as our field for this study. Dhunibehsi Municipality is the core and the Galchhi

1. Local government body means our research site's (Dhunibeshi municipality and Galchhi rural municipality) governing mechanism rural municipality is the periphery of the research site. Dhunibehsi municipality and Galchhi rural municipality cover 96.30 and $129.08 \mathrm{~km}^{2}$ respectively out of the area of $1926 \mathrm{~km}^{2}$ of Dhading (Source: Dhunibeshi Municipality and Galchhi rural municipality profile, 2020).

According to the population census 2011, it had occupied 1.26 percent (336067 including 178233 female) of the total population of Nepal (Central Bureau of Statistics [CBS], 2012). Likewise, the total population in Dhunibeshi Municipality was 36050 including 17812 female and in Galchi Rural Municipality it was 27784 including 13385 female (Dhunibeshi Municipality and Galchhi rural municipality profile, 2018). By castes figure Tamang people (19\%), occupies the greatest portion of the total population of Dhading. The Brahmin (14.98\%) and Kshatriya (14.72\%) are culturally dominant caste groups. Similarly, one of the disadvantaged caste groups, Dalit, occupies 9 percent of the total population of Dhading (CBS, 2012). Moreover, the Tamang caste is mostly found in the northern part and the southern area is the habitation of Chepang. Both of these castes are marginalized caste groups of Nepal. Moreover, Chepang is a typically indigenous caste and found in only found in Dhading, Makawanpur, Chitawan, and Nawalparasi districts. As of multi-religious feature of Nepali societies and cultural belief and practices, a pattern of multicultural way of living and livelihood practices are found in Dhading, like other parts of Nepal. In terms of religion, there is Hindu, Buddhist, Christian, Kirant, and Muslim. Out of 26 identified Dalit castes in Nepal, four Dalit castes (Kami, Damai, Sarki, and Gaine) are found in Dhading (Bishwakarma, 2017, p. 10). By occupation, Kami people mostly do their traditional smithy works. Damai people do sewing occupation and playing Panchebaja ${ }^{2}$. However, Panchaibaja is in a vulnerable condition due to the new trend of using by music bands of non-Dalit people. But unfortunately, the next one traditional job (cobbler) of Sarki had collapsed due to garmentization of leatherwork.

The Nepalese societies' livelihood practices are primarily based on agriculture including cattle rearing. As mentioned by Kharel, Khanal, and Panday (2018), a major source of fulfilling food requirements is agriculture even it contributes 29.23 percent of gross domestic production ( $p$. 2). In Dhading, except 20 percent of land covered by forest remains have been used for agricultural purpose. Most of the agricultural activities are, particularly in the hilly region including Dhading, conducted by tilling the land using oxen and artifacts made out of iron. In this regard, Kami is the primary contributor to agricultural production who rigorously produces iron tools for agricultural activities including varieties of home appliances. For other caste groups livelihood agro-based practice and various economic activities including rearing. Moreover, few people have engaged in tourism while Gangajamuna and

2. A set of musical instruments, i. e. Sahanahi, Dhalkuti, Damaha, Temko, and Jhurma played by Damai caste 
Ganesh Himal trekking trail promoted a decade ago.

\section{Building Bridge: Way Forward to Dalits' Mainstreaming Challenges}

Along with constructing the infrastructure of rural development around the countryside, it is most important to educating poor communities' children to combat poverty themselves for sustainable rural development. The more focusing on sustainability the more gaining to transform the rural world through sustainable poverty reduction. The milestone approach of lessening poverty is investing in educating children on how to deal with livelihood challenges. In this regard, a transformative viewpoint is essentially important that the rural development process is never-ending practice of social transformation. It always aims and attempts to touch the needs and problems of poor families and communities in a creative, innovative, and scientific way. It can sustain all the developmental initiatives in the course of the process and practice of dealing with poverty challenges.

Many of us might have thought that rural development is a process of utilizing resources as much as we need or can! But, as we perceive, it is, rather, a mobilization of people who have immeasurable potentialities in using indigenous knowledge and skills and to adopting technologies. Hence, it is a bridging process among available natural resources, human factors, and technologies. Moreover, it is not the process of only empowering rural people and highlighting feasibility and possibility rather an approach to combine all the possibilities and human potentialities towards economic growth, for instance, building social networks, cooperative development initiatives, educating and empowering deprived communities, and suppressed. Such initiations enhance their developmental potentialities, as a result, increased in rural productivity which may contribute to the gross national growth at the end. In such a viewpoint, rural development is a constructive and inclusive approach. As Acharya (2008) has defined rural development as an inclusive social development of rural communities and modernization of societies overall (p. 181). In doing so, as with Acharya's viewpoint, Dalit should be conscious of their own day to day social behavior. It needs to create a space to assimilate them with non-Dalit. As a result, Dalits will have access to leadership positioning in social networks and the decision-making process. Dalit socialization and mobilization are an alternative approach that brings them into the sociopolitical circle themselves as means of potential contributor to the national development. So, it is undoubtedly crucial that bridging Dalit and nonDalit into a common circle of social networks. It could be an effective approach to social transformation in the end. For this, it needs to re/correct our dualistic beliefs, culture, and practices. It might be one of the effective ways to bridging Dalits into national mainstreaming. Positivity is a powerful means against dualistic views and practices. In this regard, Buddha said "Your mind is a powerful thing. When you filter it with positive thoughts, your life will start to change." Therefore, positive thoughts always aim to change the way of misconception, fault consciousness to free us from conflicting beliefs, practice, and dualism. It could even be a way of self-transformation which leads us into paths to enlighten self to others in order to transform the world sustainably.

\section{Discussions}

Most of the developmental theories and their practices have been getting failure to address the needs of Dalit communities including minorities. Hence, rural development initiatives are yet un/helpful and un/ sustainable approach to deprived communities. It, rather, focuses on promoting the living standard of semi/elites. At this point, rural development strategy is not a connotative one if it does not address the actual needs of pro-poor lives. Rather, it seems exclusion-inclusion dualism because some traditional occupations have recently been being shifted from one caste to another. For few years, bands of non-Dalit people holding Dalit occupations, e.g. tailoring and playing Panchaibaja. On the next hand, most Dalit people are found in critically vulnerable conditions of their livelihood since garmentization and industrialization of their traditional occupations. Not many but a few non-Dalit female youth are found in tailoring mostly in rural areas, it is because of freedom in engaging any kinds of jobs for economic benefits. As with observing such scenarios can be claimed that labor division is no longer based on caste.

In this regard, Anil (2013) mentioned Ilaiah's (an Indian scholar) view in his article that caste hierarchy forms a kind of chain that will be no longer thus broken in the future (p.1). At this point, one of the examples could be such an overlapping shifting trend in occupations. Therefore, there will no more caste relying on their traditional occupations for livelihood in the future. Then, it is possible that the link between caste and occupation can be broken and yet the overlap of caste and class can be very strong (Subedi, 2013, p. 71). At this point, it does not mean to hallmarking castes based on prescribed occupations. As Pasa and Bishwokarma (2020) also highlighted that Dalit youths of Mulabari village of Dhading are not following their traditional occupational skills rather upgrading their traderelated skills before joining foreign employment.

Likewise, in such a socio-economic moment, it is needless to say that Dalits' historical occupations hallmarked them to be Dalits. For this, one participant explored his idea that:

Traditional occupation and sociocultural belief and practices are hidden reasons to exclude Dalit from national mainstreaming, I have been teaching for a decade but not getting a chance in the decision-making process of the school yet (Field-note, 10th February, 2020).

As many of us might not know about Dalit positioning 
in the socio-cultural context of the rural world how critical Dalit life is. Many of today's Brahmin falling into alcoholic addiction, bar and alcoholic business, shoeshops and garmenting, etc. whereas such occupation is totally responsible to Dalit for long past. But such a paradigm-shifting in occupations could be an example of socioeconomic and sociocultural transformation. In this vein, Shrinivas (2003) suggested that productions are being freed from caste-based division of labor. It might be the result of livelihood diversification in the contemporary life-world and rural/urban setting of multidimensional economic linkage with occupation and job-market.

Exclusion is one of the most challenging issues of the contemporary world. Even it is a harder phenomenon to deal with inclusive approach of rural development initiatives. Such socio-cultural practice has led to barricade to the social mainstreaming of not only Dalit but all deprived nationalities. In this vein, Limbu (2012) states that inequality is one of the major factors of social conflicts, thus, better to address it through inclusive development and economic growth of rural lives to prevent future conflicts (p. 2). Nevertheless, an attempt to Dalit mainstreaming in rural/national development is, at least, a prompt process of social inclusion and cutting edge of remained feudalism. The purposed aim of rural development is to improve rural area's living standards. In doing so, it needs to use the full potentialities of natural and human resources, knowledge, skills, and technologies. Itis not a joke to deal with poverty challenges rather a big agenda to cope with the hardness boundaries of rural lives. It is because; a giant picture of social discrimination has still existed there due to sociocultural boundaries. In this point, one of the participants expressed his thought that: sociocultural norms and values fosters caste-based discrimination which led Dalit to be excluded from social networks, and if they are included in the course of inclusive practice non-Dalit do not space them for vital post of the networks (field-note, March 10, 2020).

However, for a few years, an inclusive principle and practice has been taking over exclusion to empower backward communities all over the world, thanks to a group of social scientists! The term 'socialization' denotes having good assimilation within social networks. It's a process of adopting various behavior patterns of cultural premises where people act and live to survive. In a sense, assimilation is a process of togetherness. Similarly, the term 'mobilization' refers to be ready to acting or marching towards the purposed aim to have substantial benefits for social development. The togetherness of people as a social network, for instance, involvement in local clubs, International/Non-Governmental Organizations (I/ NGOs), and grass-root level governing bodies are known as activation of socialization and mobilization of people. In this regard, one of the participants expressed her experiences: It is still hard to get leadership positioning in social networks due to caste and gender-based discrimination (Field-note, February, 2020).

\section{Findings}

There are still some obstructing circles and boundaries for social mainstreaming to Dalit. Dalits are still lacking far behind in spacing leadership positioning of the social networks. Even Dalit feel harder about dealing with multidimensional sociopolitical inequalities based on caste, culture, ethnicity, gender in getting leading positioning in social networks. Although there has been empowering Dalit people it is, yet, not getting opportunities to hold the leadership positioning at any kind of social networks. Hence, it is impossible to achieve substantial economic growth and the purposed aim of sustainable development without hitting the challenges of vulnerable Dalit communities. However, the aim of rural development should be corresponding to reach its goal and uplifting the lives of rural Dalit including ethnic minorities. By reasoning, the Dalit empowerment process has to be taken into consideration as a process of sustainable rural/national development. Dalit people have to deal with multifaceted challenges. Empowering excluded communities through means of education is an important alternative approach as equal to teach how to fishing instead of providing trapped fishes.

\section{Ways for Dalit Mainstreaming: 5Es Conceptual Mapping}

As an innovative point of view, the 5Es approach developed based on discussions and findings of this study. It could be an alternatively innovative way of Dalit mainstreaming in rural development. The 5Es (envisioningeducating-empowering-ensuring-encouraging) approach has to be conceptualized and acknowledged. It needs innovatively planned developmental initiatives and processes. It principally sustains the process, pace, practice of sustainable rural development. The 5Es $(5 \&$ E) symbolically 5 denotes the number of letters of the term 'Dalit' and E denotes the fifth alphabet of A-Z. The 5Es substantially attempt to deal with poverty challenges.

First E for "envisioning” Dalit lives through a new rural development perspective, which helps us to insight real situation of Dalits' living vulnerability. Second E for "educating" Dalit children for flourishing their future might lead them to combat with discrimination challenges themselves. Third E for "empowering" Dalit people through multidimensional approach itself strengthens them to contest with traditionally constructed, discriminative sociocultural beliefs and values. Fourth E for "ensuring" Dalit rights and emphasizing in implementation in dayto-day life situation, participatory policy advocacy and decision-making process may enhance their consciousness to envision constitutional provision and state mechanism accordingly. Fifth E for "encouraging" them by state and 
self-inspiration may bring Dalit to be well mainstreaming in the rural development process.

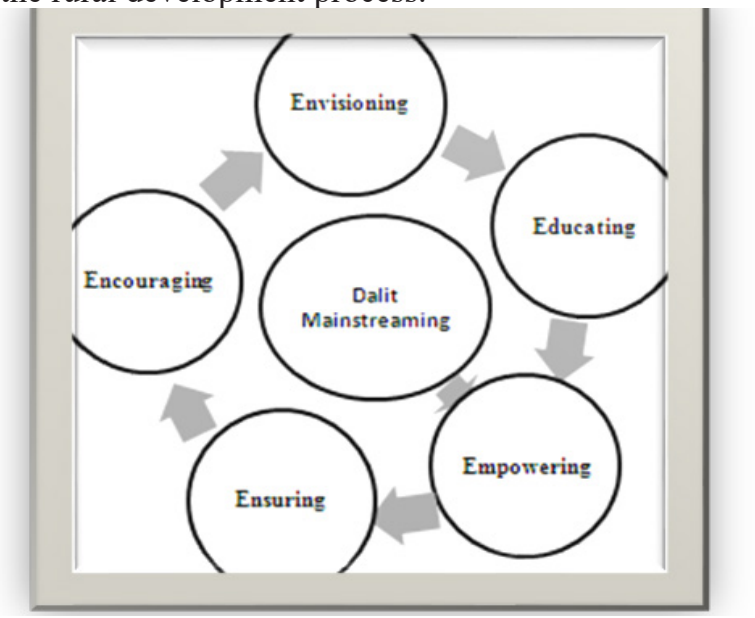

Figure 1: 5Es Conceptual Mapping for Dalit Mainstreaming

All these ways are absolutely connected model approach for promoting Dalit lives. It is a never-ending process to envisioning-educating-empowering-ensuringencouraging to promote Dalit in rural development mainstreaming. Therefore, 5Es approach can be defined as a cyclic method like cycling towards the destination that any individual wants to reach hook and crook. The wheels of the cycle never get fatigue and expect the rest until it reaches the destination. The wheels are themselves cycled beyond having rest of its interest if he or she doesn't want to have rest until reach them. Because it is not as the journey of the cycle without goals rather any journey with a goal to reach the intended destination. For a few decades, the ongoing changing context and concept of rural people and new perspective of rural development attempts to practice inclusiveness among caste, gender, and ethnic diversity. It's a green signal of flourishing rural development outcomes. Educating children in such a way that they could innovatively deal with poverty challenges is important. It is because children are a potential source of creative development and a sustainable future.

Hence, we affirm that Dalit mainstreaming is possible with effective implementation of 5Es alternative approach (Figure 1). Dalit mainstreaming is a way of lifting the rural development process. It is because poverty is around them. Without hitting Dalits' livelihoods challenges no ways to meet the aim of prosperity. Educating Dalit to empower them is could be another new space for implementing rural development strategies in the federal context. It is the right time to eradicate inequalities since exclusivism is being overtaken by inclusivism. In doing so, all the deprived nationalities have to be accounted for national mainstreaming in order to meet the dream of a prosperous, happiest, and wealthy nation. In the course of federalism, all nationalities are equally identified and bring them into the sustainable development process. It itself empowers people from all over the national territories and nationalities. For this, the government has already been extensively dispersed its voice "Nepal as a country of wealthy, healthy, happy, and prosperous!"

\section{Conclusion and Policy Implication}

To sum up, it is the fact that the huge mass of people including Dalit were out of the circle (still a reality) of rural development mainstreaming. As a result, getting leadership positioning in social networks and development initiatives for Dalit is still harder. A fact is that Dalits are still lagging behind in the process of national development. Hence, rural development strategy should, at least, be Dalit friendly/centered to address their livelihood challenges. It needs proper and meaningful socialization and mobilization of Dalit. However, the government and its partner agencies (I/NGOs) tend to support monetarily but money is not enough in solving all problems created by socio-cultural beliefs, norms, and values. However, it is a green signal of Dalit empowerment and eliminating social inequalities. Finally, 5Es alternative rural development approach could be one of the best means of combating poverty challenges. It is the model that is not only for mainstreaming Dalits through their quality leadership positioning but could be an alternative approach for other so-called underprivileged ethnic groups who have been struggling against rampant poverty challenges.

\section{Acknowledgments:}

Heartfelt thanks to the research participants for cooperating with our research issues, providing their valuable time, and sharing their reflective experiences. We are thankful to the anonymous manuscript reviewers for their constructive comments and suggestions. We are also thankful to Mr. Megh Vilash Bhatta for editing the language of this manuscript.

\section{Funding:}

This research study was conducted under the selfefforts of the researchers and not received grant support from any government and non-government agencies.

\section{Ethical Approval for the Research:}

Ethical approval for this study was granted by the participants during member checking.

\section{Conflict of Interest:}

The researchers do not have any kind of conflict of interest.

\section{Ethical Conduct of Research:}

We declare that the research was conducted ethically. 


\section{References}

Acharya, B. (2008). Dimension of rural development in Nepal. Dhaulagiri Journal of Sociology and Anthropology, 2, 181-192.

Anil, M. R. (2013).The process of Dalitization: A brief sociocultural reading of Kanchha Ilaiah. International Journal of Science and Research (IJSR), 5(9), 12921296.

Badal, B. (2017). Social welfare model of rural development. Nepalese Journal of Development and Rural Studies, 14(1-2), 1-11. https://doi.org/10.3126/ njdrs.v14i1-2.19642

Bishwakarma, L. (2017). Caste-based discrimination in schooling: A narrative inquiry. Nepalese Journal of Development and Rural Studies, 14(1-2), 56-62. https://doi.org/10.3126/njdrs.v14i1-2.19648

Bishwakarma, L. (2020). Education to transform castebased values and practices in Nepal: Focusing on holistic care for village people. Studies in Holistic Education/Care. Japanese Society for Holistic Education/Care, 23, 81-88.

Central Bureau of Statistics. (2012). The population census of Nepal, 2011. CBS, Kathmandu.

Chaudhary, P. K., \& Pasa, R. B. (2015). Agriculture Education for Rural Development in Nepal. Journal of Training and Development, 1, 38-45. https://doi. org/10.3126/jtd.v1i0.13089

Connelly, F. M., \& Clandinin, D. J. (1990). Stories of experience and narrative inquiry. Educational Researcher, 19(5), 2-14.

Creswell, J. W. (2014). Research design: Qualitative, quantitative and mixed methods approaches (4th ed.). Sage.

Denzin, N. K., and Lincoln, Y. S. (2011). Handbook of qualitative research (4th ed.). Sage.

Dhunibeshi Municipality. (2020). Dhunibeshi municipality profile. Dhunibeshi Municipality.

Dumont, L. (1980). The hierarchicus: The caste system and its implications. University Press.

Galchhi Rural Municipality. (2020). Galchhi rural municipality profile. Galchhi Rural Municipality.

Jayaram V. (n.d.). The Vedic gods. Retrieved from https:// www.scribd.com/document/6550138/Rig-Vedic-Gods

Khanal, S., Kharal, B., \& Pandey, D. (2018). Assessment of soil fertility under different land-use systems in Dhading District of Nepal, (Vol. 2nd). https://doi. org/10.3390/soilsystems2040057

Limbu, P. R. (2012). Gender issues and Dalit farmers in Surkhet effects of vegetable seed project at Mehelkuna VDC, SurKhet, Mid-western region of Nepal. Van Hall Larenstein University of Applied Science, Wageningen, Netherlands.

Luitel, B. C. (2009). Culture, worldview and transformative philosophy of mathematics education in Nepal: A cultural-philosophical inquiry (An Unpublished
Doctoral Dissertation, Curtain University).

Curtain, Australia: Department of Technology.

O'reilly, K. (2005). Ethnographic methods. Routledge.

Pasa, R. B., and Bishwokarma, J. B. (2020).

Microeconomic analysis of remittance in Mulabari village of Galchhi, Nepal. IOSR Journal of

Humanities and Social Science (IOSR-JHSS), 25(3), 20-26. https://doi:10.9790/0837-2503042026

Shahi, S. (2017). Understanding vikas: How Dalit make sense of development in rural Nepal. Nepalese Journal of Development and Rural Studies, 14(1-2), 98-111. https://doi.org/10.3126/njdrs.v14i1-2.19653

Shrestha, M. (2009). Community development. Quest Publication.

Srinivas, M. N. (2003). An obituary on caste as a system'. Economic and Political Weekly, 38(5), 455-60.

Webster, L., and Mertova, P. (2007). Using narrative inquiry as a research method: An introduction to using critical event narrative analysis in research on learning and teaching. Routledge.

Rajan Binayek Pasa (https://orcid.org/0000-0001-88867714) (Ph.D. in Education, 2019 and Ph.D. Scholar in Rural Development) is Assistant Professor at Central Department of Rural Development (CDRD), Tribhuvan University, University Campus Kirtipur Kathmandu. Besides, he has been serving as a coordinator of Self Study Report preparation committee of CDRD that is formed under Quality Accrediation Assurance project of University Grants Commission Nepal. Pasa's publications within education and social sciences are more focused on transformative role of education, employability of technical education and vocational training, agriculture transformation, ecotourism and rural tourism development issues.

Email:rajan.pasa@cdrd.tu.edu.np

Lila Bahadur Bishwakarma (https://orcid.org/00000002-4199-6444) (MPhil in Educational Leadership and Master Degree in Education) is senior teacher (1993 to date) at Kallery Secondary School (community based) located in Dhading District. Being a local intellectual and Dalit empowerment activist he has been playing agency role in Dalit community and beyond. Besides, he is a research member of Japanese Society for holistic education/ care since 2018 that has been providing school educational opportunities to the children belong to socio-economically back warded family. Bishwakarma's publications are more focused on social transformation related issues such as community empowerment, Dalit empowerment and traditional cultural reproduction practices of Nepalese society. Email:vishwakarmalila@gmail.com 